\title{
Effect of chlorocomplex of lead on the deposition of lead-bearing barite from hot spring water
}

\author{
BOKUICHIRO TAKANO \\ Institute of Chemistry, College of General Education, \\ University of Tokyo, Komaba, Meguroku, Tokyo. \\ (Received January 8, 1969; in revised form August 25, 1969)
}

\begin{abstract}
The behavior of barium and lead in Tamagawa Hot Spring water has been discussed. Compared with barite of hydrothermal origin, barite from hot spring water is singular in its lead content. This fact was elucidated in terms of lead chlorocomplex formation in the spring water from which barite precipitates. The experimental verification has been attempted on the deposition of this mineral.
\end{abstract}

\section{INTRODUCTION}

Barite is common gangue mineral in hydrothermal ore deposits and is generally almost pure $\mathrm{BaSO}_{4}$. Strontium, calcium, magnesium and sometimes lead replace barium and they are usually found as minor constituents. In an extreme case, strontium is present up to $28 \%$ as $\mathrm{SrO}$ and this mineral is called strontiobarite (Palache et al., 1951). According to GrahmanN (1920), formation of a complete solid solution between $\mathrm{BaSO}_{4}$ and $\mathrm{SrSO}_{4}$ is possible. In contrast to the $\mathrm{BaSO}_{4}-\mathrm{SrSO}_{4}$ system, however, a solid solution between $\mathrm{BaSO}_{4}$ and $\mathrm{PbSO}_{4}$ has been unknown in hydrothermal ore deposits (MinamI, 1930), until Takano (1959) found it in barite from hot springs.

Окамото (1906) found a radioactive barite containing $30 \%$ of $\mathrm{PbSO}_{4}$, deposited on rocks in a stream of hot spring water of Hokuto Hot Springs, Formosa. Similar deposits have also been found at Tamagawa Hot Springs, Akita, Japan. These minerals from both hot springs were found to be similar in chemical composition and are considered to deposit through the same mechanism.

Barite from Tamagawa Hot Springs contains lead from 1 to $16 \%$ by weight. Lead-poor barite is a large white crystal, while lead-rich one is less crystalline and has a zonal structure of white and brownish layers. The first comprehensive study on hokutolite* was performed by Suganuma (1930), who made total chemical analysis of

* The definition of this mineral was somewhat obscure. TAKANO(1959) found that lattice constants of lead-bearing barites do not obey Vegard's rule and their composition is between $\mathrm{A}_{25} \mathrm{~B}_{75}$ and $\mathrm{A}_{75} \mathrm{~B}_{25}\left(\mathrm{~A}=\mathrm{PbSO}_{4}, \mathrm{~B}=\mathrm{BaSO}_{4}\right)$. He proposed that barite within this range is to be called "hokutolite". According to this, barite from Tamagawa Hot Springs is not "hokutolite" In the present paper, however, the author calles it hokutolite just for convenience. 
hokutolite. He also paid attention to its zonal structure of alternative layers and considered that this structure is closely related to the mechanism of formation of this mineral. Furthermore, he noticed that the hokutolite from Tamagawa Hot Springs changes its lead content along with locality, and attributed this to variation in acidity of spring waters.

For the discussion of this phenomenon, it is necessary to know the barium and lead contents of the water in each locality where hokutolite deposits. But available data on the barium and lead contents of the spring water are not enough to discuss this point. In the present paper the variation in lead content of hokutolite will be elucidated in terms of the chlorocomplex formation.

\section{EXPERIMENTAL}

(a) Determination of barium in waters

Two liters of sample solutions was taken. Five $\mathrm{ml}$ of concentrated sulfuric acid and $375 \mathrm{mg}$ of strontium as chloride were added to them. Solutions were left overnight. Precipitates were collected by decantation and brought to laboratory. Barium coprecipitated with $\mathrm{SrSO}_{4}$ was determined by X-ray fluorescent spectroscopy (TAKANO, 1969).

(b) Determination of lead in waters and synthesized ( $\mathrm{Ba}, \mathrm{Pb}_{\mathrm{SO}} \mathrm{SO}_{4}$

Lead in hot spring waters was determined colorimetrically by dithizone method (SAITo and TAKEUCHI, 1961). ( $\mathrm{Ba}, \mathrm{Pb}$ ) $\mathrm{SO}_{4}$ was first boiled with $30 \% \mathrm{Na}_{2} \mathrm{CO}_{3}$ solution and converted to carbonate, which was washed several times with dilute $\mathrm{Na}_{2} \mathrm{CO}_{3}$ solution and then decomposed by nitric acid. Lead in the solution was determined in the same way as described above.

(c) Preparation of ( $\mathrm{Ba}, \mathrm{Pb}) \mathrm{SO}_{4}$

Homogeneous precipitation of $\mathrm{BaSO}_{4}$ with sulfamic acid was applied in this case from the point of view that the sedimentation rate of hokutolite is very small. Experiments were performed at two temperatures, 60 and $80^{\circ} \mathrm{C}$. In the former case $150 \mathrm{mg}$ of sulfamic acid, $120 \mathrm{mg}$ of $\mathrm{Ba}^{2+}$ and $60 \mathrm{mg}$ of $\mathrm{Pb}^{2+}$ as nitrate and in the latter case $60 \mathrm{mg}, 100 \mathrm{mg}$ and $100 \mathrm{mg}$ of each reagent respectively were placed in a $100 \mathrm{ml}$ Erlenmeyer flask, and then several aliquots of sodium chloride solution were added to vary the chloride concentration from $0.01 \mathrm{M}$ to $2 \mathrm{M}$. The solution was diluted to $100 \mathrm{ml}$ after adding a few drops of nitric acid until the $\mathrm{pH}$ value of the solution became 1.2. Then the solution was stirred magnetically and kept at a constant temperature for a day or four days.

\section{RESUltS AND Discussion}

Fig. 1 shows a sketch map of Tamagawa Hot Springs together with the sampling localities of spring waters for the determination of barium and lead. 


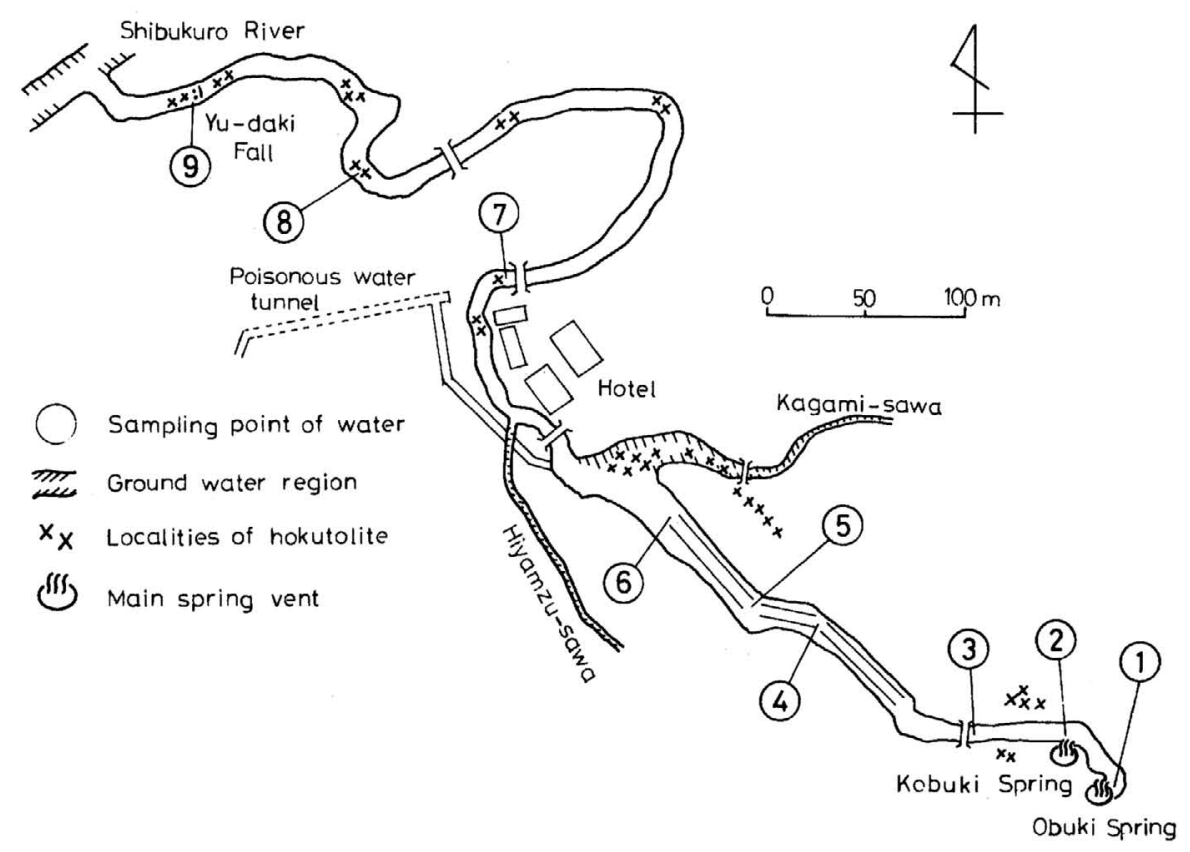

Fig.1. Tamagawa Hot Springs.

\section{(a) Lead content of hokutolite from Tamagawa Hot Springs}

It was noticed by Suganuma (1930) and Minami (1953) that barite from Tamagawa changes its lead content with its locality. There is a general tendency for the lead content to increase along with the distance from the vent of Obuki Spring (Table 1). This tendency was accounted for by Suganuma in terms of the solubility of $\mathrm{PbSO}_{4}$. ICHIKUNI (1966) estimated the barium content of the stream water by calculations based on the partition coefficient of lead between solution and barium sulfate precipitates and concluded that the major portion of barium in the original solution precipitates as $\mathrm{BaSO}_{4}$ within $100 \mathrm{~m}$ from Obuki Spring. His estimation seems to imply that the increase in the lead content of barite precipitates is attributed to the decrease in the barium concentration in the water, compared with the lead concentration in the water, but in this respect he neglected the effect of the dilution by ground water. The decrease in the barium concentration of the spring water may not directly mean

Table 1. Variation in $\mathrm{Pb} / \mathrm{Ba}$ weight ratios of barite from Tamagawa Hot Springs with the distance from the vent of Obuki Spring

\begin{tabular}{llccc}
\hline \hline $\begin{array}{c}\text { Distance } \\
(\text { meter })\end{array}$ & $0 \sim 100$ & $200 \sim 400$ & $500 \sim 600$ & $600 \sim 700$ \\
$\begin{array}{c}\mathrm{Pb} / \mathrm{Ba} \\
\left(\mathrm{x} 10^{2}\right)\end{array}$ & $1 \sim 8$ & $14 \sim 20$ & $22 \sim 26$ & $28 \sim 31$ \\
\hline
\end{tabular}


the precipitation of barium as $\mathrm{BaSO}_{4}$. For the further discussion on this point, it is necessary to obtain data on the barium and lead content of the spring water at each locality along the stream.

(b) Barium and lead content of water

Suganuma (1930) gave the values $0.65 \mathrm{mg} \mathrm{Ba} / 1$ and $0.61 \mathrm{mg} \mathrm{Pb} / 1$ for the water issuing from the vent of Obuki Spring. MinAMI and OYAGI (1963) determined the barium content of the water to be $2.9 \mathrm{mg} / 1$ (1953) and $5.7 \mathrm{mg} / 1$ (1954) by means of flame photometry.

For the lead content of that water, $1.53 \mathrm{mg} / 1$ was given by the Iwate Hygene Laboratory (1953) and $1.1 \mathrm{mg} / \mathrm{l}$ by MinAmi et al. (1957). To ascertain experimentally the behavior of barium and lead in stream waters, concentrations of both elements were determined at nine sampling locations shown in Fig. 1. Table 2 shows the barium and lead contents of the water collected on July 21,1965 . They apparently decrease,

Table 2. Barium and lead contents of Tamagawa Hot Spring water

\begin{tabular}{cccc}
\hline Sample point & $\begin{array}{c}\mathrm{Ba} \\
(\mathrm{mg} / \mathrm{l})\end{array}$ & $\begin{array}{c}\mathrm{Pb} \\
(\mathrm{mg} / \mathrm{l})\end{array}$ & $\begin{array}{c}\text { Temperature } \\
\left({ }^{\circ} \mathrm{C}\right)\end{array}$ \\
\hline 1 & 0.82 & 1.59 & 97.8 \\
2 & 0.96 & 1.51 & 98.2 \\
3 & 0.85 & 1.49 & 82.0 \\
4 & 0.85 & 1.50 & 83.0 \\
5 & 0.80 & 1.28 & 77.0 \\
6 & 0.80 & 1.28 & - \\
7 & 0.16 & 0.32 & 27.0 \\
8 & 0.23 & 0.35 & 25.5 \\
9 & 0.18 & 0.32 & 25.5 \\
\hline
\end{tabular}

as the original water flows down, but the mixing of ground water must be taken into consideration. To avoid the effect of dilution, $\mathrm{Ba} / \mathrm{Cl}$ and $\mathrm{Pb} / \mathrm{Cl}$ ratios in each water were discussed. Fig. 2 shows that these ratios are almost constant everywhere in the stream studied. $\mathrm{The} \mathrm{Pb} / \mathrm{Ba}$ ratios of the water are apparently constant. In this respect, however, it must be borne in mind that these data show the total quantities of both elements in waters. Barium was determined in very small microcrystals of hokutolite suspended in water as well as dissolved in water. In fact, these microcrystals were recognized under a microscope in sulfurous sinters precipitated on the stream bed, or on the bottom sand of Obuki Spring. As the flow rate of the spring water is considerably high, the major portion of microcrystals is carried away. They are too small to adhere to the surface of bed rocks.

From this point of view, it is impossible to discuss accurately the behavior of 

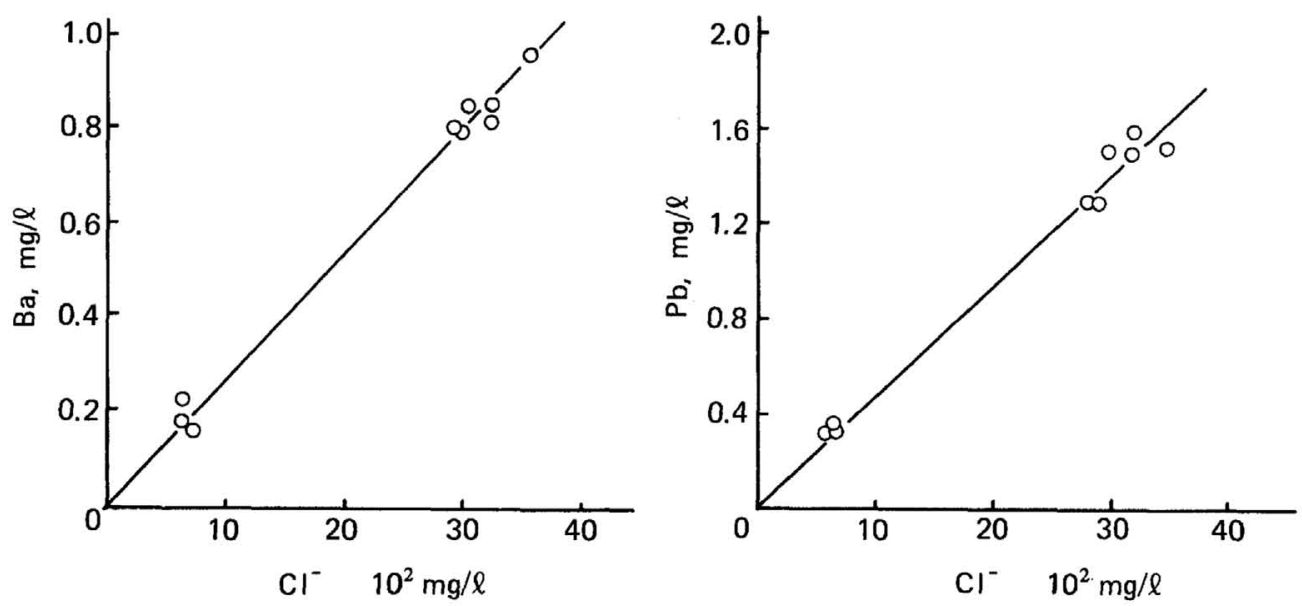

Fig.2. Change in total $\mathrm{Ba}$ and $\mathrm{Pb}$ content with $\mathrm{Cl}^{-}$content in spring waters.

barium and lead dissolved in water without the knowledge of solubility of barite under these conditions.

The solubility of hokutolite in the solution, of which composition is similar to that of the water from Obuki Spring, were determined to be $0.50 \mathrm{mg} \mathrm{Ba}^{2+} / 1$ at $83^{\circ} \mathrm{C}$ and $0.79 \mathrm{mg} \mathrm{Ba}^{2+} / 1$ at the boiling point of the solution (TAKANO, 1969). The original water seems to be slightly supersaturated with barium sulfate.

(c) Some consideration of the contribution of lead complexes in the spring waters

to $\mathrm{Pb} / \mathrm{Ba}$ ratios of hokutolite

$\mathrm{Pb} / \mathrm{Ba}$ ratio of Hokutolite is affected by $a_{\mathrm{Pb}^{2}} / a_{\mathrm{Ba}^{2+}}$ ratios of spring waters. If the activity ratio of free barium and lead ions increases, $\mathrm{Pb} / \mathrm{Ba}$ ratio of precipitates will increase proportionally.

The complex formation of lead will decrease the activity of free lead ions which in part coprecipitate with $\mathrm{BaSO}_{4}$. The chloro- and thio- complexes are considered generally to be major lead complexes in hot spring water. The formation of thiocomplexes, however, could be neglected in the solutions low in $\mathrm{H}_{2} \mathrm{~S}$ content as in the Tamagawa Hot Spring waters (average $\mathrm{H}_{2} \mathrm{~S}$ content $2 \mathrm{mg} / \mathrm{l}$ ).

ICHIKUNI (1966) referred to the possibility that the complex formation of lead might modify the activity of free lead ions in the solution, since it contains a considerable amount of chloride ions. Although he neglected this possibility in his calculation, it becomes clear from following calculation that the formation of chlorocomplexes of lead affects $\mathrm{Pb} / \mathrm{Ba}$ ratios of barite precipitates.

It is well known that lead forms $\mathrm{PbCl}^{+}, \mathrm{PbCl}_{2}{ }^{\circ}, \mathrm{PbCl}_{3}{ }^{-}$and $\mathrm{PbCl}_{4}{ }^{2-}$ in chloride solution. The proportion of the contents of complexes and free lead ions to the total lead content of spring waters are estimated from the next five equations, 


$$
\begin{aligned}
& m_{\text {total } \mathrm{Pb}}=m_{\mathrm{Pb}^{2+}}+m_{\mathrm{PbCl}^{+}}+m_{\mathrm{PbCl}_{2}}^{\circ}+m_{\mathrm{PbCl}_{3}^{-}}+m_{\mathrm{PbCl}_{4}{ }^{2-}} \\
& \frac{m_{\mathrm{Pb}^{2+} \gamma_{\mathrm{Pb}^{2+}} m_{\mathrm{Cl}^{-}} \gamma_{\mathrm{Cl}^{-}}}^{m_{\mathrm{PbCl}} \gamma_{\mathrm{PbCl}}}}{\mathrm{Pb}^{-}}=K_{1} \\
& \frac{m_{\mathrm{PbCl}^{+}} \gamma_{\mathrm{PbCl}^{+}} m_{\mathrm{Cl}^{-} \gamma_{\mathrm{Cl}^{-}}}}{m_{\mathrm{PbCl}_{2}}{ }^{\circ} \gamma_{\mathrm{PbCl}_{2}}{ }^{\circ}}=K_{2} \\
& \frac{m_{\mathrm{PbCl}_{2}}{ }^{\circ} \gamma_{\mathrm{PbCl}_{2}}{ }^{\circ} m_{\mathrm{Cl}^{-}} \gamma_{\mathrm{Cl}^{-}}}{m_{\mathrm{PbCl}_{3}{ }^{-} \gamma_{\mathrm{PbCl}_{3}}}}=K_{3} \\
& \frac{m_{\mathrm{PbCl}_{3}{ }^{-}} \gamma_{\mathrm{PbCl}_{3}^{-}} m_{\mathrm{Cl}^{-}} \gamma_{\mathrm{Cl}^{-}}}{m_{\mathrm{PbCl}_{4}{ }^{2-} \gamma_{\mathrm{PbCl}_{4}{ }^{2-}}}}=K_{4},
\end{aligned}
$$

where $m_{\mathrm{X}}$ is the molality of $\mathrm{X}$-th constituent, $\gamma_{\mathrm{X}}$ its activity coefficient and $K_{\mathrm{n}}$ its dissociation constant. $m_{\mathrm{Cl}^{-}}$is considered to be $m_{\mathrm{Cl}^{-}}$total.$\quad m_{\mathrm{Pb} \text { total }}$ and $m_{\mathrm{Cl}^{-}}$total of spring waters are known from analytical data.

HELGESON (1964) summarized the data on the dissociation constants of lead chlorocomplexes and furthermore he estimated the temperature dependence of these constants from the solubility data of $\mathrm{PbCl}_{2}$. These constants are available at 25 and $80^{\circ}$ C. ${ }^{*}$ Each temperature roughly corresponds to those of Obuki Spring and Yu-daki Fall waters, respectively. Activity coefficients may be calculated by the Debye-Hückel equation, if the ionic strength $I$ of a solution is as much as 0.1 . The chemical compositions of spring waters of the two representative localities are given in Table 3 , from which the values of the ionic strength are obtained; $I_{\mathrm{O}}=0.12$ and $I_{Y}=0.028$, where the suffix $\mathrm{O}$ refers to Obuki Spring and $\mathrm{Y}$ to Yu-daki Fall.

From these results, it may be reasonable to apply the D-H equation (6)** for the calculation of activity coefficient, $\gamma_{\mathrm{i}}$.

$$
-\log \gamma_{\mathrm{i}}=\frac{A z_{\mathrm{i}}^{2} \sqrt{I}}{1+\stackrel{\circ}{a}_{\mathrm{i}} B \sqrt{I}},
$$

where $\stackrel{\circ}{a}_{\mathrm{i}}$ was assumed to be independent of temperature.

* Dissociation constants of lead chlorocomplexes used here are as follows; at $25^{\circ} \mathrm{C}, K_{1}=2.69 \times 10^{-2}, K_{2}=6.60 \times 10^{-2}, K_{3}=1.30, K_{4}=2.0$ at $80^{\circ} \mathrm{C}, K_{1}=1.59 \times 10^{-2}, K_{2}=1.41, K_{3}=5.6, K_{4}=1.2 \times 10^{-1}$. (After Helgeson (1964))

** For constants in equation (6) were employed the next values: At $25^{\circ} \mathrm{C}, A=0.509, B=0.329$. At $80^{\circ} \mathrm{C}, A=0.574, B=0.342$. $\stackrel{\stackrel{a}{a}}{\mathrm{i}}=6$ for $\mathrm{PbCl}^{+}, \mathrm{PbCl}_{3}{ }^{-}$and $\mathrm{PbCl}_{4}{ }^{2-}, 5$ for $\mathrm{Ba}^{2+}, 4.5$ for $\mathrm{Pb}^{2+}$ and 3 for $\mathrm{Cl}^{-}$. 
Table 3. Chemical composition of Tamagawa Hot Spring water (Date: July 21, 1965)

\begin{tabular}{lcc}
\hline \hline & \multicolumn{2}{c}{ Locality } \\
& Obuki Spring & Yu-daki Fall \\
\hline $\mathrm{Na}^{+}$ & $110 \mathrm{mg} / \mathrm{l}$ & $18.5 \mathrm{mg} / \mathrm{l}$ \\
$\mathrm{K}^{+}$ & 21.5 & 10.0 \\
$\mathrm{Ca}^{2+}$ & 168 & 37.0 \\
$\mathrm{Mg}^{2+}$ & 46.9 & 30.7 \\
$\mathrm{Fe}$ (total) & 85.5 & 20.0 \\
$\mathrm{Al}^{3+}$ & 99.1 & 26.9 \\
$\mathrm{Cl}^{-}$ & 3174 & 625 \\
$\mathrm{SO}_{4}{ }^{2-}$ & 96.1 & 170 \\
$\mathrm{HSO}_{4}{ }^{-}$ & 1158 & 178 \\
$\mathrm{pH}$ & 1.2 & 1.7 \\
\hline
\end{tabular}

Table 4. Calculated distribution of the lead chlorocomplexes in the spring waters

\begin{tabular}{c|cc}
\hline Locality & $\begin{array}{c}\text { Obuki Spring } \\
\text { (mole per cent) }\end{array}$ & $\begin{array}{c}\text { Yu-daki Fall } \\
\text { (mole per cent) }\end{array}$ \\
\hline $\mathrm{Pb}^{2+}$ & 38 & 71 \\
$\mathrm{PbCl}^{+}$ & 60 & 24 \\
$\mathrm{PbCl}_{2}{ }^{\circ}$ & 2 & 5 \\
$\mathrm{PbCl}_{3}{ }^{-}$ & $<0.1$ & $<0.1$ \\
$\mathrm{PbCl}_{4}{ }^{2-}$ & & \\
\hline
\end{tabular}

Using these values, one can obtain activity $a_{\mathrm{Pb}^{2+}}$ for Obuki and Yu-daki Fall, where the total lead contents are $0.725 \times 10^{-5}$ and $0.159 \times 10^{-5} \mathrm{~mol} / 1$ and the chloride contents are $89.52 \times 10^{-3}$ and $17.63 \times 10^{-3} \mathrm{~mol} / 1$, respectively. The mole per cent of each complex is given in Table 4 . Thus the activity ratios of free lead ions and barium ions for the two representative regions are $\left(a_{\mathrm{Pb}^{2+}} / a_{\mathrm{Ba}^{2+}}\right)_{\mathrm{Obuki}}=0.42$, and $\left(a_{\mathrm{Pb}^{2+}} a_{\mathrm{Ba}^{2+}}\right.$ Yu-daki Fall $=0.81$, respectively. Therefore,

$$
\frac{\left(a_{\mathrm{Pb}^{2+}} / a_{\mathrm{Ba}^{2+}}\right)_{\mathrm{Yu}-\text { daki Fall }}}{\left(a_{\mathrm{Pb}^{2+}} / a_{\mathrm{Ba}^{2+}}\right)_{\mathrm{Obuki}}}=1.9
$$

This shows that the free lead ion concentration in the Yu-daki Fall region is about twice as much as that in the Obuki Spring region, so that barite in the Yu-daki Fall region is likely to incorporate more lead than does that in the Obuki Spring region. 
Furthermore, it may be considered that free lead content of spring waters with respect to barium will become larger than 2 since the free barium content of the Yu-daki Fall region may be less than the determined value.

In Tamagawa Hot Springs, yearly and even daily variations in the chemical composition of original spring water were observed by some authors (SAHARA, 1959, WATANUKI, 1959 and IWASAKI et al., 1963). But in the first approximation, the total salt concentration and the ratio of barium and lead concentrations of the original water can be considered to be constant. Moreover, the considerable variation in temperature of that water was not observed through a year (Suganuma, 1930). Consequently, it is presumed that the nature of waters in the Obuki Spring region is similar to that of waters used for the above discussion.

On the other hand, although the ratio of barium and lead concentrations of waters in the Yu-daki Fall region is also considered to be constant, the total salt concentration and temperature of the waters show seasonal variations resulting from confluence of some streamlets. In addition, the topography of Tamagawa Hot Springs was greatly changed on account of repeated constructions for the removal of poisonous spring waters (MiURA, 1964, see Fig. 1). Therefore, the nature of the waters in this region is now considerably different from that at the time when hokutolite was deposited.

Taking into account of these two sorts of variations, at the time before the constructions, the temperature and the total salt concentrations of waters in the Yu-daki Fall region are presumed to have been about $40^{\circ} \mathrm{C}$ and a half of the total salt concentration of the present original water, respectively.* Under these conditions, recalculations were made in the similar way on the $\gamma_{i}$ 's of dissolved ions and the proportion of each lead complex to the total lead of water in the Yu-daki Fall region. In this case, a value of 1.8 was obtained from the equation (7).

Experimental results as shown in Fig. 3 qualitatively support the above estimation, but lead content of $\mathrm{BaSO}_{4}$ precipitated at $60^{\circ} \mathrm{C}$ is smaller than that of $\mathrm{BaSO}_{4}$ at $80^{\circ} \mathrm{C}$. This seemed to be contrary to the general rule in coprecipitation phenomena. It is well known that the amount of coprecipitation is influenced by the speed of formation of the precipitate, which in turn is a function of the concentration of the ion being precipitated and the concentration of the precipitating agent, the presence of foreign substances affecting the solubility and the temperature during the precipitation.

In our experiments, the $\mathrm{pH}$ value and the $\mathrm{Pb} / \mathrm{Ba}$ weight ratio of the original solution were kept constant before each run. The speed of the precipitation, in this case, almost depended upon temperature, since the producing rate of a precipitating agent, $\mathrm{SO}_{4}{ }^{2-}$, was determined by the rate of hydrolysis of sulfamic acid. Therefore, two plots in Fig. 3 mean that the amount of coprecipitation increases as the chloride ion concentration of the solution decreases and the speed of precipitation rises. The

* Data used here were obtained by MINAMI et al. in 1953 when the drainage of poisonous water was stopped. 


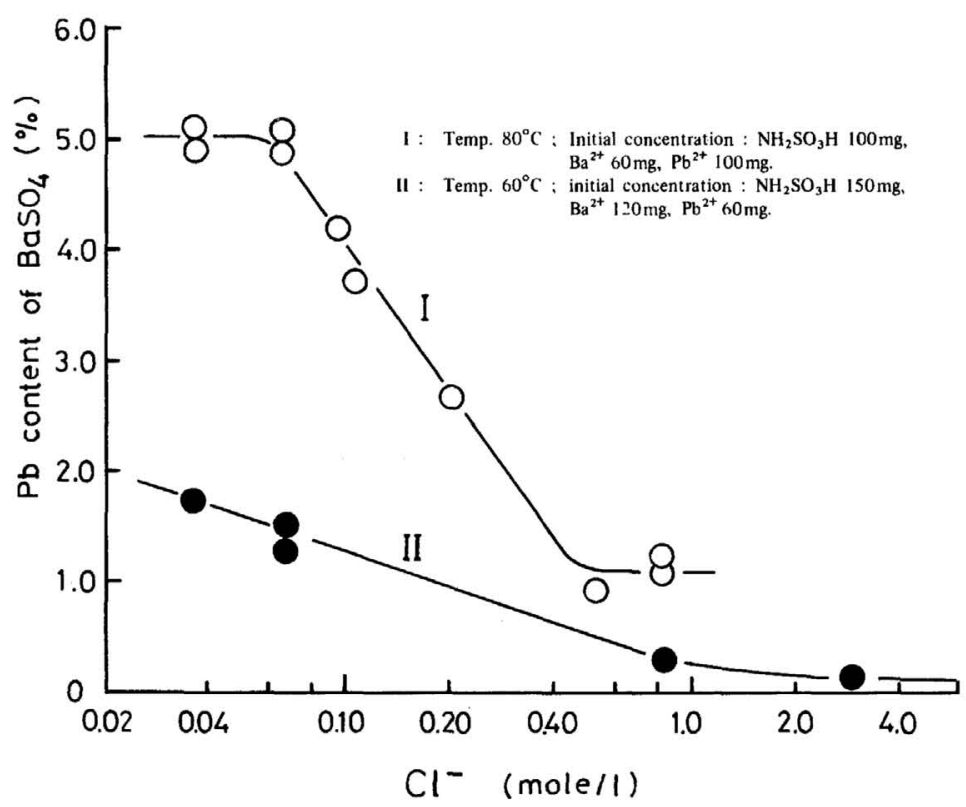

Fig.3. Change in $\mathrm{Pb}$ content of $\mathrm{BaSO}_{4}$ with $\mathrm{Cl}^{-}$ concentration of solutions.

precipitates were found to be monophase by X-ray powder diffraction pattern. If, in addition, the $\mathrm{Pb} / \mathrm{Ba}$ weight ratio of the solution becomes larger, each plot will have a steeper slope. The $\mathrm{Pb} / \mathrm{Ba}$ ratios of the spring waters are about 1.8 and hence the conditions for the coprecipitation of lead becomes more favorable in the spring waters.

\section{CONCLUSION}

The lead content of barite from Tamagawa Hot Springs changes with its locality. This may be due to the three factors, the increase of free lead ions in the spring waters through the dissociation of lead complexes by confluence of some streamlets, the speed of the precipitation and presumably the decrease in concentration of free barium ion resulting from precipitation of microcrystals of barite. In general, barite from hydrothermal ore deposits does not contain an appreciable amount of lead although it is often associated with lead minerals such as galena. This might be accounted for by the similar reasoning since the ore-forming solution is considered to contain usually a few moles of chloride ions.

\section{ACKNOWLEDGMENTS}

The author expresses his sincere appreciations to Prof. KIMIO NOGUCHI and Prof. MASAMI ICHIKUNI of Tokyo Metropolitan University. 


\section{REFERENCES}

GrahmanN, W. (1920) Über Barytocölestin und das Verhältnis von Anhydrit zu Cölestin und Baryt. Neues Jahrb. Min. 1, 1-23.

HELGESON, H. C. (1964) Complexing and hydrothermal ore deposition (2nd edition). Pergamon. ICHIKUNI, M. (1966) The barium content of barite-forming hydrothermal waters as exemplified by Tamagawa Hot Spring waters. Bull. Chem. Soc. Japan 39, 898-901.

IWASAKI, I., Katsura, T., Tarutani, T., OZaWa, T., Yoshida, M., IWASAKi, B., Hirayama, M. and KamadA, M. (1963) Geochemical studies on Tamagawa Hot Spring. Geochemistry of Tamagawa Hot Springs. Tokyo.

MinAmI, E. (1930) Barite from Japan. Chishitsu-gaku Zasshi 37, 289-290 (in Japanese).

MinAmI, E. (1953) Hokutolite at Tamagawa Hot Springs. Research Reports Tamagawa Hot Springs 5, 1-17 (in Japanese).

MinAMI, E. and OYAGI, Y. (1963) Hokutolite at Tamagawa Hot Springs. Geochemistry of Tamagawa Hot Springs. Tokyo.

MinAmi, E., SATO, G. and WATANUKI, K. (1957) Arsenic- and lead- contents of Tamagawa Hot Spring waters. Nippon Kagaku Zasshi 78, 1096-1100 (in Japanese).

MiURA, H. (1964) History of the removal of poisonous waters at Tamagawa Hot Springs. Kogyo Yosui 71, 9-17 (in Japanese).

Oкамото, Y. (1906) Reference cited in Oкамото, Y. (1912) Supplement to Wada's Mineral of Japan 178 (in Japanese).

Palache, C., Berman, H. and Frondel, C. (1951) Dana's system of mineralogy, Vol.2, Wiley. SAHARÄ, R. (1959) Repts. Research Inst. Natural Resource, Akita Univ., 20, 15-18 (in Japanese).

SAITO, K. and TAKEUCHI, T. (1961) Determination of trace amount of lead in uranium metal by A. C. polarography and spectrophotometry. Japan Analyst 10, 152-156 (in Japanese).

Suganuma, I. (1930) On the chemical composition and the deposition of hokutolite, Akita. Tokyo Butsuri Gakko Zasshi 469, 58-93 (in Japanese).

TAKANO, Y. (1959) X-ray study of hokutolite. Kobutsu-gaku Zasshi 469, 255-276 (in Japanese).

TAKANO, B. (1969) Barium and lead content of Tamagawa Hot Spring Waters, Akita. Sci. Pap. Coll. Gen. Educ. Univ. Tokyo 19, 81-86.

WATANUKI, K. (1959) Daily variation of the components of spring water at Obuki and Ryuryoseki. Research Reports Tamagawa Hot Springs 5, 18-18 (in Japanese). 